\title{
USING ORDERED WEIGHT AVERAGING (OWA) FOR MULTICRITERIA SOIL FERTILITY EVALUATION BY GIS (CASE STUDY: SOUTHEAST IRAN)
}

\author{
Marzieh Mokarram ${ }^{1 *}$, Majid Hojati² \\ ${ }^{1 *}$ Department of Range and Watershed Management, College of Agriculture and Natural Resources of Darab, Shiraz \\ University, Iran, Email: m.mokarram@shirazu.ac.ir \\ ${ }^{2}$ Department of GIS and RS, University of Tehran, Faculty of Geography, Dep. of RS \& GIS, \\ Email:majid.hojati@ut.ac.ir
}

Corresponding author: Marzieh Mokarram, Tel.: +98-917-8020115; Fax: +987153546476 , Address: Darab, Shiraz university, Iran, Postal Code: 71946-84471, Email: m.mokarram@shirazu.ac.ir

\begin{abstract}
The Multicriteria Decision Analysis (MCDA) and Geographical Information Systems (GIS) are used to provide accurate information on Pedogenic processes and facilitate the work of decision makers. So, 15 MCDA and GIS, can provide a wide range of decision strategies or scenarios in some procedures. One of the popular algorithm of multicriteria analysis is Ordered Weighted Averaging (OWA). The OWA procedure depends on some parameters, which can be specified by means of fuzzy. The aim of this study is to take the advantage of the incorporation of fuzzy into GIS-based soil fertility analysis by OWA in west Shiraz, Fars province, Iran. For the determination of soil fertility maps, OWA 20 parameters such as potassium $(\mathrm{K})$, phosphor $(\mathrm{P})$, copper $(\mathrm{Cu})$, iron $(\mathrm{Fe})$, manganese $(\mathrm{Mn})$, organic carbon (OC) and zinc (Zn) were used. After generated interpolation maps with Inverse Distance Weighted (IDW), fuzzy maps for each parameter were generated by the membership functions. Finally, with OWA six maps for fertility with different risk level were made. The results show that with decreasing risk (no trade-off), almost all of the parts of the study area were not suitable for soil fertility.

25 While increasing risk, more area was suitable in terms of soil fertility in the study area. So using OWA can generate many maps with different risk levels that lead to different management due to the different financial conditions of farmers.
\end{abstract}

Keywords: Multicriteria Decision Analysis (MCDA); Ordered weighted averaging (OWA); fuzzy; Soil fertility. 


\section{Introduction}

Spatial planning involves decision-making techniques that are associated with techniques such as Multi Criteria Decision Analysis (MCDA) and multicriteria Evaluation (MCE). Combining GIS with MCDA methods creates a powerful tool for spatial planning (Malczewski, 1999; Shumilov et al., 2011; Kanokporn \& Iamaram, 2011; Belkhiri et al., 2011; Salehi et al., 2012; Feng et al., 2012; Ashrafi et al., 2012). Multicriteria evaluation may be used to develop and evaluate alternative plans that may facilitate compromise among interested parties (Malczewski, 1996). In general, the GIS-based soil fertility analysis assumes that a given study area is subdivided into a set of basic units of observation such as polygons or rasters. Then, the soil fertility problem involves evaluation and classification of the areal units according to their fertility for a particular activity. There are two fundamental classes of multicriteria evaluation methods in GIS: The Boolean overlay operations (none compensatory combination rules) and the weighted linear combination (WLC) methods (compensatory combination rules). These approaches can be generalized within the framework of the ordered weighted averaging (OWA) (Asproth et al., 1999; Jiang and Eastman, 2000; Makropoulos et al., 2003; Malczewski et al., 2003; Malczewski \& Rinner, 2005; Malczewski .,2006). OWA is a family of multicriteria combination procedures (Yager, 1988). Conventional OWA can utilizes the qualitative statements in the form of 45 fuzzy quantifiers (Yager, 1988, 1996). The main goal of this paper is to produce the land suitability maps according to OWA operators for GIS-based multicriteria evaluation procedures.

OWA has been developed as a popularization of multicriteria combination by Yager (1988). The OWA concept has been extended to the GIS applications by Eastman (1997) as a part of decision support module in GIS-IDRISI. Subsequently, Jiang and Eastman (2000) demonstrate the utility of the GIS-

OWA for land use/suitability problems. The implementation of the OWA concept in IDRISI15.01 resulted in several applications of OWA to environmental and urban planning problems (Asprothet al., 1999; Mendes \& Motizuki, 2001). 
Solid Earth Discuss., doi:10.5194/se-2016-17, 2016

Manuscript under review for journal Solid Earth

Published: 2 March 2016

(c) Author(s) 2016. CC-BY 3.0 License.

(c) (1)

Mokarram and Aminzadeh (2010) used OWA for land suitability in Shavur plain, Iran. The results showed that OWA is a multicriteria evaluation procedure (or combination operator). The quantifierguided OWA procedure is illustrated using land-use suitability analysis in Shavur plain, Iran.

Liu and Malczewski (2013) used GIS-Based Local Ordered Weighted Averaging in London, Ontario. In the study area, the aim was to implement local form of OWA. The local model was based on the range sensitivity principle. The results showed that there were substantial differences between the spatial patterns generated by the global and local OWA methods.

60 Accordingly, the study area is one of the most important centers of agriculture in Iran, and the aim of the study is the determination of produce the soil fertility maps according to OWA operators for GISbased multicriteria evaluation procedures in southeast Iran using OWA. In the study, we expected that the selected OWA method is the best method for the determination of multicriteria soil fertility. According to OWA method the amount of soil fertility with different risk levels was determined that is useful for farmers with different financial conditions.

\section{Methods}

In order to prepare soil fertility maps using OWA method, 45 sample soils were used that after the creation of the interpolation maps for each parameters using Inverse Distance Weighted (IDW) and the creation of a fuzzy parameter map for each parameter, in order to make different risk levels OWA was used. The description of each method is in the following:

\subsection{Inverse Distance Weighted (IDW)}

IDW model was used for interpolating Effective data in determining of soil fertility such as potassium $(\mathrm{K})$, phosphor $(\mathrm{P})$, copper $(\mathrm{Cu})$, iron $(\mathrm{Fe})$, manganese $(\mathrm{Mn})$, organic carbon $(\mathrm{OC})$ and zinc $(\mathrm{Zn})$. IDW

75 interpolation explicitly implements the assumption that things that are close to one another are more alike than those that are farther apart. To predict a value for any unmeasured location, IDW will use the 
Solid Earth Discuss., doi:10.5194/se-2016-17, 2016

Manuscript under review for journal Solid Earth

Published: 2 March 2016

(c) Author(s) 2016. CC-BY 3.0 License.

(c) (1)

measured values surrounding the prediction location. Assumes value of an attribute $z$ at any unsampled point is a distance-weighted average of sampled points lying within a defined neighborhood around that unsampled point. Essentially it is a weighted moving average (Burrough, et al., 1998):

$\hat{z}\left(x_{0}\right)=\frac{\sum_{i=1}^{n} z\left(x_{i}\right) \mathrm{d}_{i j}^{-r}}{\sum_{i=1}^{n} \mathrm{~d}_{i j}^{-r}}$

Where $x_{0}$ is the estimation point and $x_{i}$ are the data points within a chosen neighborhood. The weights $(r)$ are related to distance by $d_{i j}$.

\subsection{Ordered Weight Average (OWA)}

OWA is a multicriteria evaluation procedure. The nature of the OWA procedure depends on some parameters, which can be specified by fuzzy quantifiers. The GIS-based multicriteria evaluation procedures involve a set of spatially defined alternatives and a set of evaluation criteria represented as map layers. According to the input data (criterion weights and criterion map layers), the OWA combination operator associates with the i- th location (e.g., raster or point) a set of order weights $\mathrm{v}=$ $\mathrm{v}_{1}, \mathrm{v}_{2}, \ldots, \mathrm{v}_{\mathrm{n}}$ such that $\mathrm{v}_{\mathrm{j}} \in[0,1], \mathrm{j}=1,2 \ldots, \mathrm{n}, \sum_{j=1}^{N} v_{j}=1$, and is defined as follows (see Yager, 1988; Malczewski et al., 2003):

$$
O W A_{t}=\sum_{j=1}^{N}\left(\frac{\mathrm{u}_{j} \mathrm{v}_{j}}{\sum_{j=1}^{n} \mathrm{u}_{j} \mathrm{v}_{j}}\right) z_{t f}
$$

95 where $z_{i 1} \geq z_{i 2} \geq \ldots \geq z_{i n}$ is the sequence obtained by reordering the attribute values $a_{i 1}, a_{i 2}, \ldots, a_{i n}$, and $u_{j}$ is the criterion weight reordered according to the attribute value, $z_{i j}$. It is important to point to the difference between the two types of weights (the criterion weights and the order weights). The criterion 
weights are assigned to evaluation criteria to indicate their relative importance. All locations on the $j$-th criterion map are assigned the same weight of $w_{j}$. The order weights are associated with the criterion values on the location-by-location basis. They are assigned to the $i$-th location's attribute value in decreasing order without considering from which criterion map the value comes. With different sets of order weights, one can generate a wide range of OWA operators including the most often used GISbase map combination procedures: the weighted linear combination (WLC) and Boolean overlay operations, such as intersection (AND) and union (OR) (Yager, 1988; Malczewski et al., 2003). The AND and OR operators represent the extreme cases of OWA and they correspond to the MIN and MAX operators, respectively. The order weights associated with the MIN operator are: $v_{n}=1$, and $v_{j}=0$ for all other weights. Given the order weights, $\mathrm{OWA}_{\mathrm{i}}(\mathrm{MIN})=\operatorname{MIN}_{\mathrm{j}}\left(a_{i 1}, a_{i 2}, \ldots, a_{i n}\right)$. The following weights are associated with the MAX operator: $v_{l}=1$, and $v_{j}=0$ for all other weights, and consequently $\mathrm{OWA}_{\mathrm{i}}(\mathrm{MAX})=\operatorname{MAX}_{\mathrm{j}}\left(a_{i l}, a_{i 2}, \ldots, a_{i n}\right)$. Assigning equal order weights (that is, $v_{j}=1 / n$ for $j=1,2, \ldots$

, n) results in the conventional WLC, which is situated at the mid-point on the continuum ranging from the MIN to MAX operators (Table 1) (Malczewski, 2006).

Table 1. Properties of Regular Increasing Monotone (RIM) quantifiers with selected values of Parameter (source: Malczewski, 2006).

\begin{tabular}{|c|c|c|c|c|c|}
\hline$\alpha$ & $\begin{array}{c}\text { Quantifier } \\
(\boldsymbol{Q})\end{array}$ & Order Weights $(\boldsymbol{v}$ ik $)$ & $\begin{array}{l}\text { GIS } \\
\text { Combination } \\
\text { Procedure }\end{array}$ & ORness & rade-off \\
\hline$\alpha \rightarrow=$ & At least one & Vi1=1; vik=0, $(1<\mathrm{k}<=\mathrm{n})$ & OWA (OR) & 1.0 & 0 \\
\hline$\alpha=0.1$ & At least a few & a & OWA & $\mathrm{a}$ & $\mathrm{a}$ \\
\hline$\alpha=0.5$ & A few & $\mathrm{a}$ & OWA & $\mathrm{a}$ & $\mathrm{a}$ \\
\hline$\alpha=1$ & Half (identity) & vik $=1 / \mathrm{n}, 1<=\mathrm{k}<=\mathrm{n}$ & OWA (WLC) & 0.5 & 1 \\
\hline$\alpha=2$ & Most & $\mathrm{a}$ & OWA & $\mathrm{a}$ & $\mathrm{a}$ \\
\hline$\alpha=10$ & Almost all & $\mathrm{a}$ & OWA & $\mathrm{a}$ & $\mathrm{a}$ \\
\hline$\alpha \rightarrow \infty$ & All & Vin $=1 ; \operatorname{vik}=0,(1<=\mathrm{k}<\mathrm{n})$ & OWA (AND) & 0 & 0.0 \\
\hline
\end{tabular}


Solid Earth Discuss., doi:10.5194/se-2016-17, 2016

Manuscript under review for journal Solid Earth

Published: 2 March 2016

(c) Author(s) 2016. CC-BY 3.0 License.

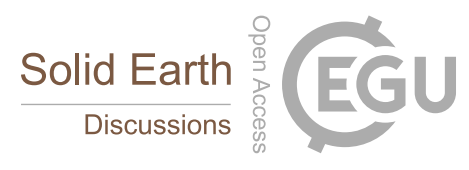

(c) (1)

\section{3. Case study}

This study was carried out in west Shiraz, Fars province, Iran. It is an area of about $100.02 \mathrm{~km}^{2}$, and is located at longitude of $\mathrm{N} 29^{\circ} 31^{\prime}-29^{\circ} 38^{\prime}$ and latitude of E $52^{\circ} 49^{\prime}$ to $52^{\circ} 57^{\prime}$ (Figure 1). The altitude of the study area ranges from the lowest of $1,571 \mathrm{~m}$ to the highest of 2,203 $\mathrm{m}$. The main agricultural produce consists of grain, fruit, and vegetables, while the partly wooded mountains are used for 120 pasture. 


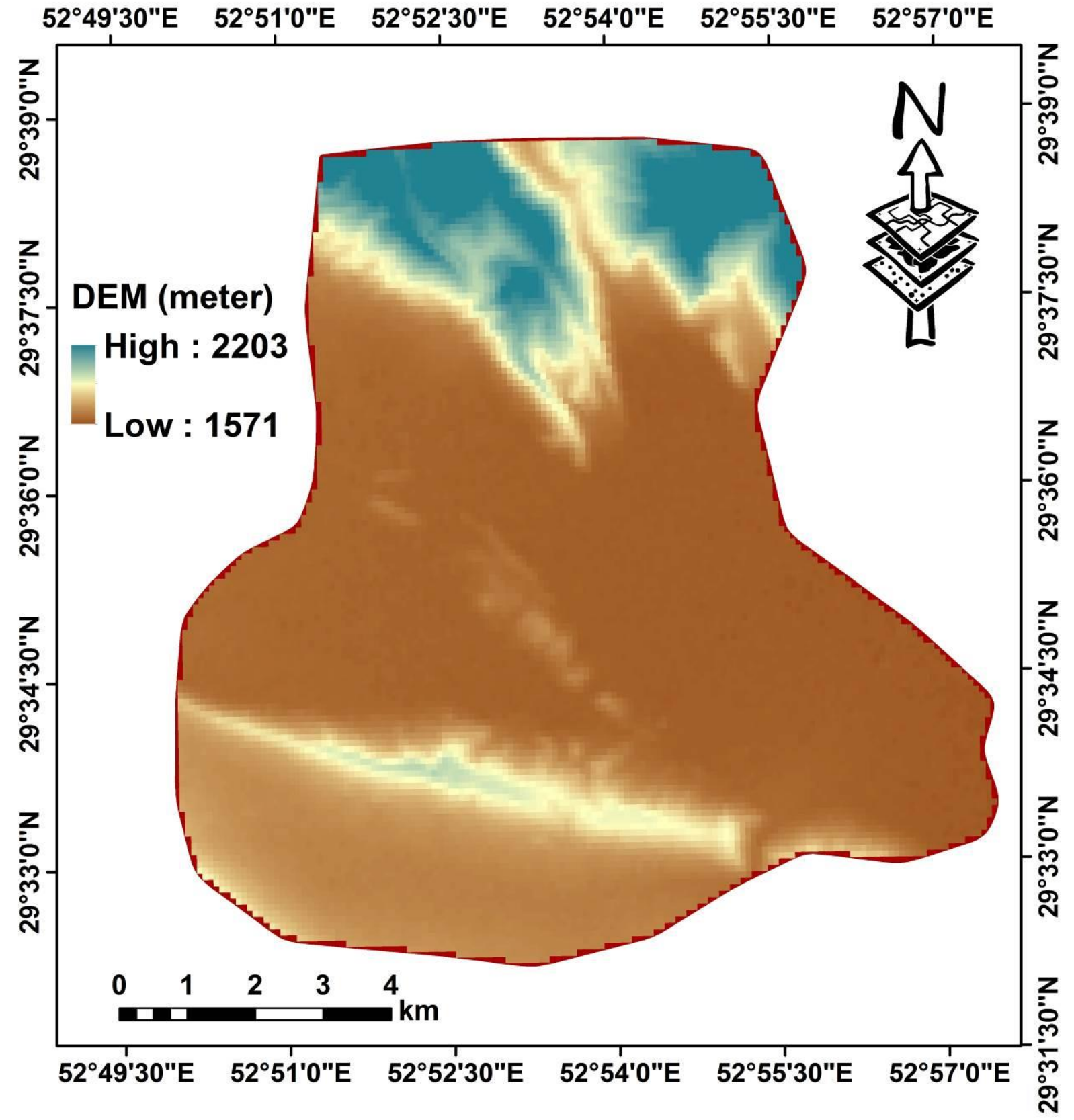

Figure 1. Location of the study area (digital elevation model (DEM) with spatial resolution of $30 \mathrm{~m}$ ) (Source: http://earthexplorer.usgs.gov). 
The assessment of soil fertility for agricultural production in the region is vital, which should consider environmental factors and human conditions (Soufi, 2004). In order to predict the variability of soil fertility, $\mathrm{P}, \mathrm{K}, \mathrm{Cu}, \mathrm{Fe}, \mathrm{Mn}, \mathrm{OC}$ and $\mathrm{Zn}$ maps were prepared (Table 2) (Organization of Agriculture Jahad Fars province).

Table 2. Descriptive statistics of the data for soil fertility (Organization of Agriculture Jahad Fars province)

\begin{tabular}{cccccccc}
\hline $\begin{array}{c}\text { Statistic } \\
\text { parameters }\end{array}$ & $\begin{array}{c}\mathrm{OC} \\
(\mathrm{mg} / \mathrm{kg})\end{array}$ & $\begin{array}{c}\mathrm{P} \\
(\mathrm{mg} / \mathrm{kg})\end{array}$ & $\begin{array}{c}\mathrm{K} \\
(\mathrm{mg} / \mathrm{kg})\end{array}$ & $\begin{array}{c}\mathrm{Fe} \\
(\mathrm{mg} / \mathrm{kg})\end{array}$ & $\begin{array}{c}\mathrm{Zn} \\
(\mathrm{mg} / \mathrm{kg})\end{array}$ & $\begin{array}{c}\mathrm{Mn} \\
(\mathrm{mg} / \mathrm{kg})\end{array}$ & $\begin{array}{c}\mathrm{Cu} \\
(\mathrm{mg} / \mathrm{kg})\end{array}$ \\
\hline maximum & 1.65 & 30.00 & 666.00 & 15.00 & 3.00 & 52.50 & 2.00 \\
minimum & 0.18 & 2.00 & 137.00 & 1.00 & 0.10 & 2.80 & 0.20 \\
average & 1.01 & 13.94 & 313.73 & 4.54 & 0.65 & 14.77 & 0.97 \\
STDEV & 0.35 & 6.49 & 104.28 & 2.84 & 0.50 & 10.71 & 0.36 \\
\hline
\end{tabular}

\section{Results and Discussion}

\subsection{Inverse Distance Weighted (IDW)}

135 In the study area for the determination of soil fertility 45 sample points were used. This data was prepared by the Organization of Agriculture Jahad Fars province in 2012. In the study spline, inverse distance weighted (IDW) and simple krining method (gaussian, circular, spherical, exponential model) were used for the production of raster maps for each soil parameter in ArcGIS 10.2. The results of rootmean-square deviation (RMSE) for three models showed that IDW method (circular model) with 140 lowest RMSE is the best model for the prediction of soil parameters. According to Figure 2 sample points was selected randomly in the study area. In the study area the IDW interpolation was used for produces in order to predict of $\mathrm{K}, \mathrm{P}, \mathrm{Cu}, \mathrm{Fe}, \mathrm{Mn}, \mathrm{OC}$ and $\mathrm{Zn}$ that are shown in Figure 3. According to Figure 3, most elements in the north and parts of south of the study area were determined to have lower amounts than the other regions. 


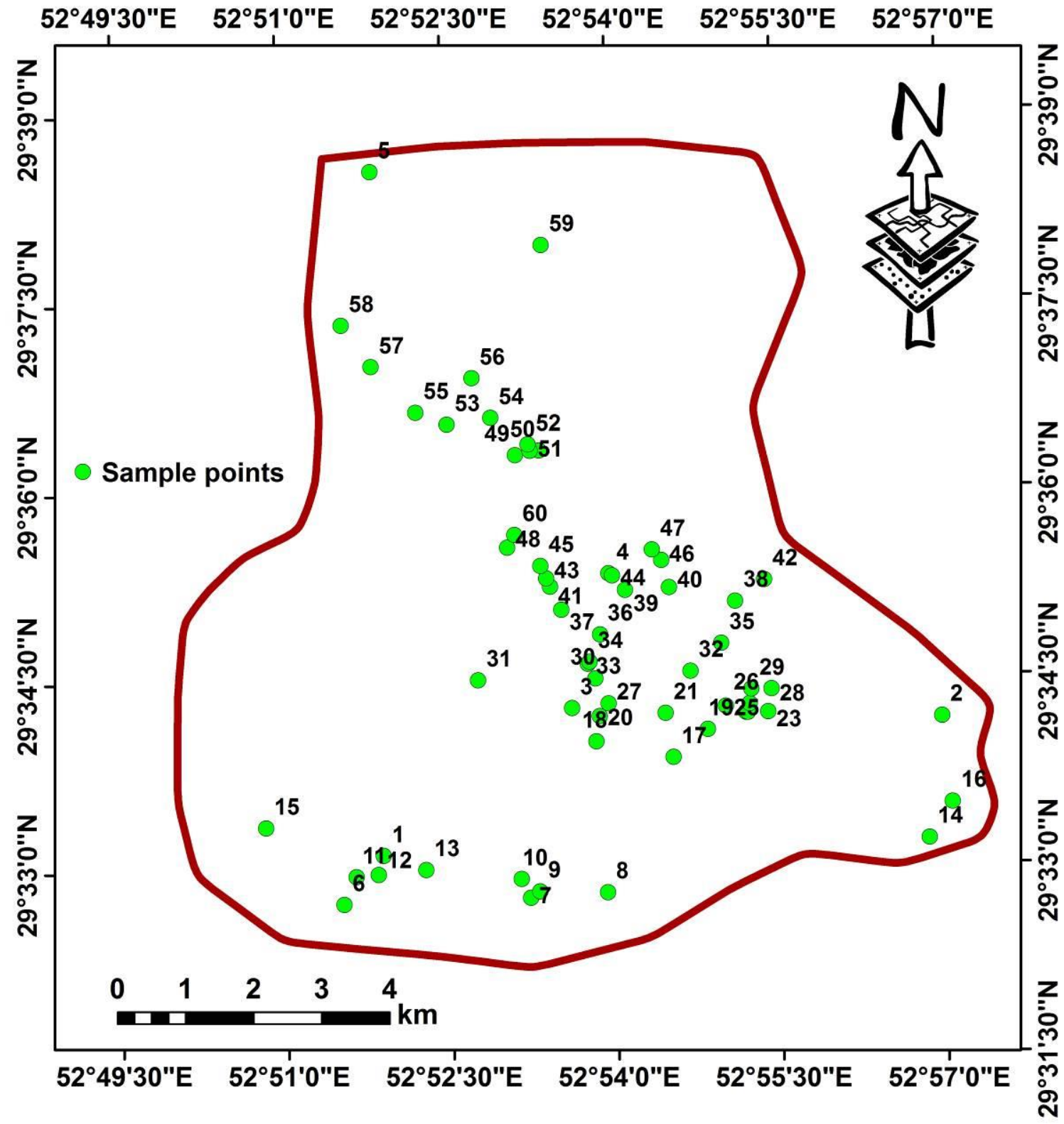

Figure 2. Position of sample points for the study area. 
Solid Earth Discuss., doi:10.5194/se-2016-17, 2016

Manuscript under review for journal Solid Earth

Published: 2 March 2016

(c) Author(s) 2016. CC-BY 3.0 License.

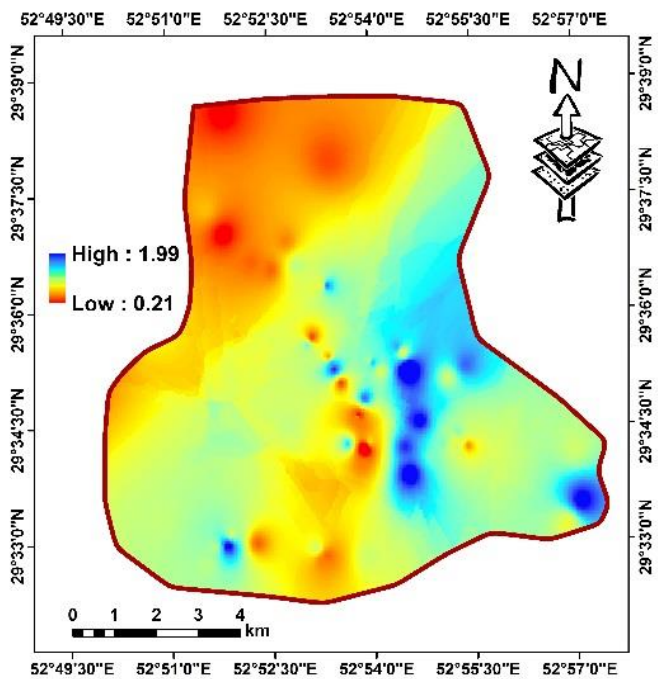

Potassium (K) IDW Map(a)

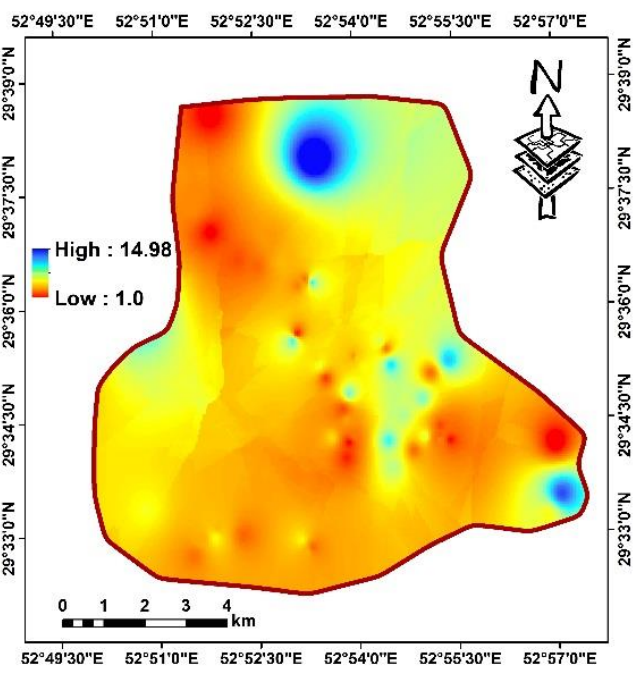

Phosphor (P) IDW Map(b)

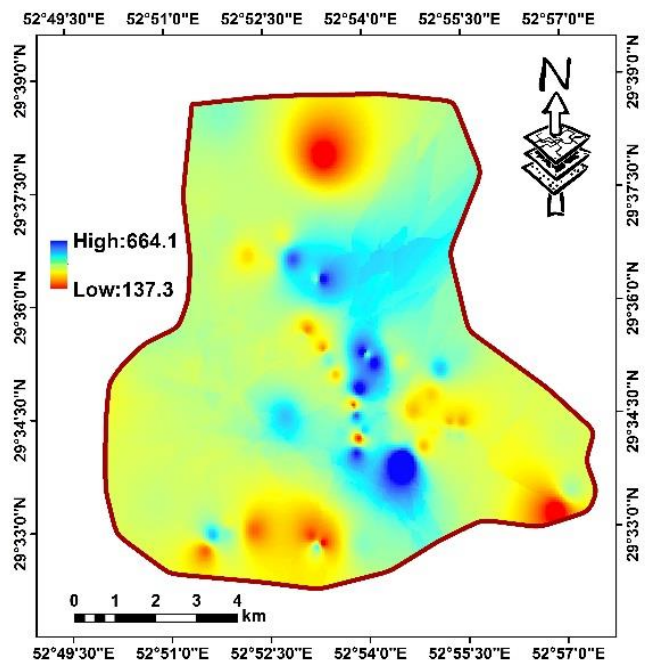

Cu IDW Map (c)

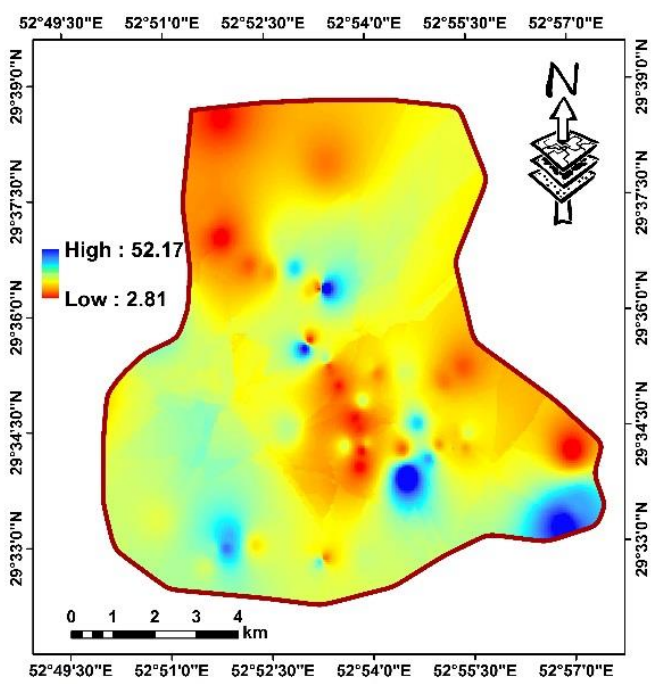

Fe IDW Map(d) 
Solid Earth Discuss., doi:10.5194/se-2016-17, 2016

Manuscript under review for journal Solid Earth

Published: 2 March 2016

(c) Author(s) 2016. CC-BY 3.0 License.

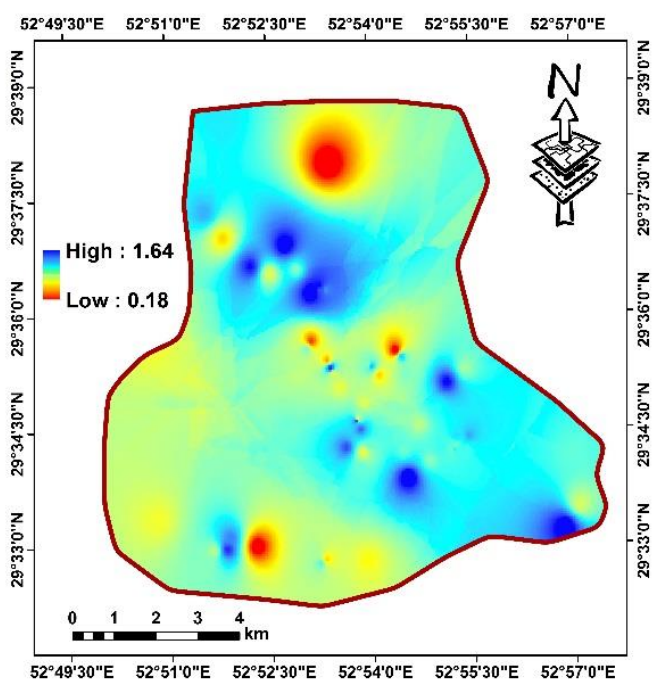

Mn IDW MAP(e)

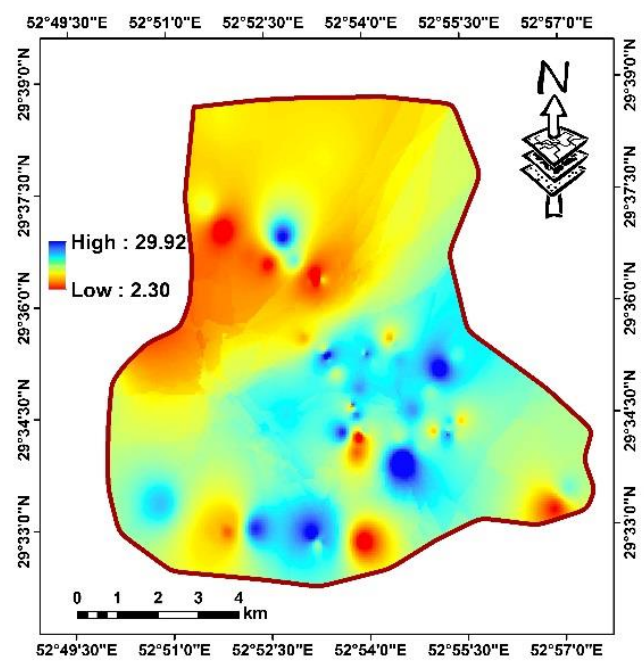

OC IDW MAP(f)

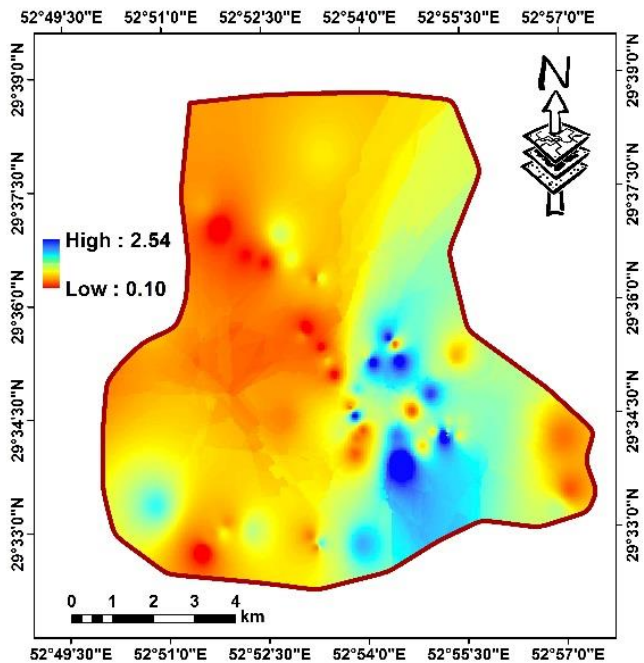

\section{Zn IDW MAP(g)}

Figure 3. Interpolation map using IDW method. (a):K; (b):P (c):CU, (d):Fe; (e):Mn; (f):OC; (g): Zn.

\subsection{Fuzzy method}

150 In this study, $\mathrm{P}, \mathrm{K}, \mathrm{Cu}, \mathrm{Fe}, \mathrm{Mn}, \mathrm{OC}$ and $\mathrm{Zn}$ maps from IDW were used as input to fuzzy inference system. In order to homogenize each parameter for weightedness by OWA method for preparing the final soil fertility fuzzy method was used. According to FAO (1983) membership function for each 
Solid Earth Discuss., doi:10.5194/se-2016-17, 2016

Manuscript under review for journal Solid Earth

Published: 2 March 2016

(c) Author(s) 2016. CC-BY 3.0 License.

(c) (i)

parameter was defined $(\mathrm{K}, \mathrm{P}, \mathrm{Cu}, \mathrm{Fe}, \mathrm{Mn}, \mathrm{OC}$ and $\mathrm{Zn})$ and each of fuzzy map was created for each elements between 0 to 1 . The prepared fuzzy maps for the soil fertility parameters are shown in Figure 155 4, where MF is closer to 0 with decreasing soil fertility, while MF is closer to 1 with increasing soil fertility (Soroush et al., 2011).

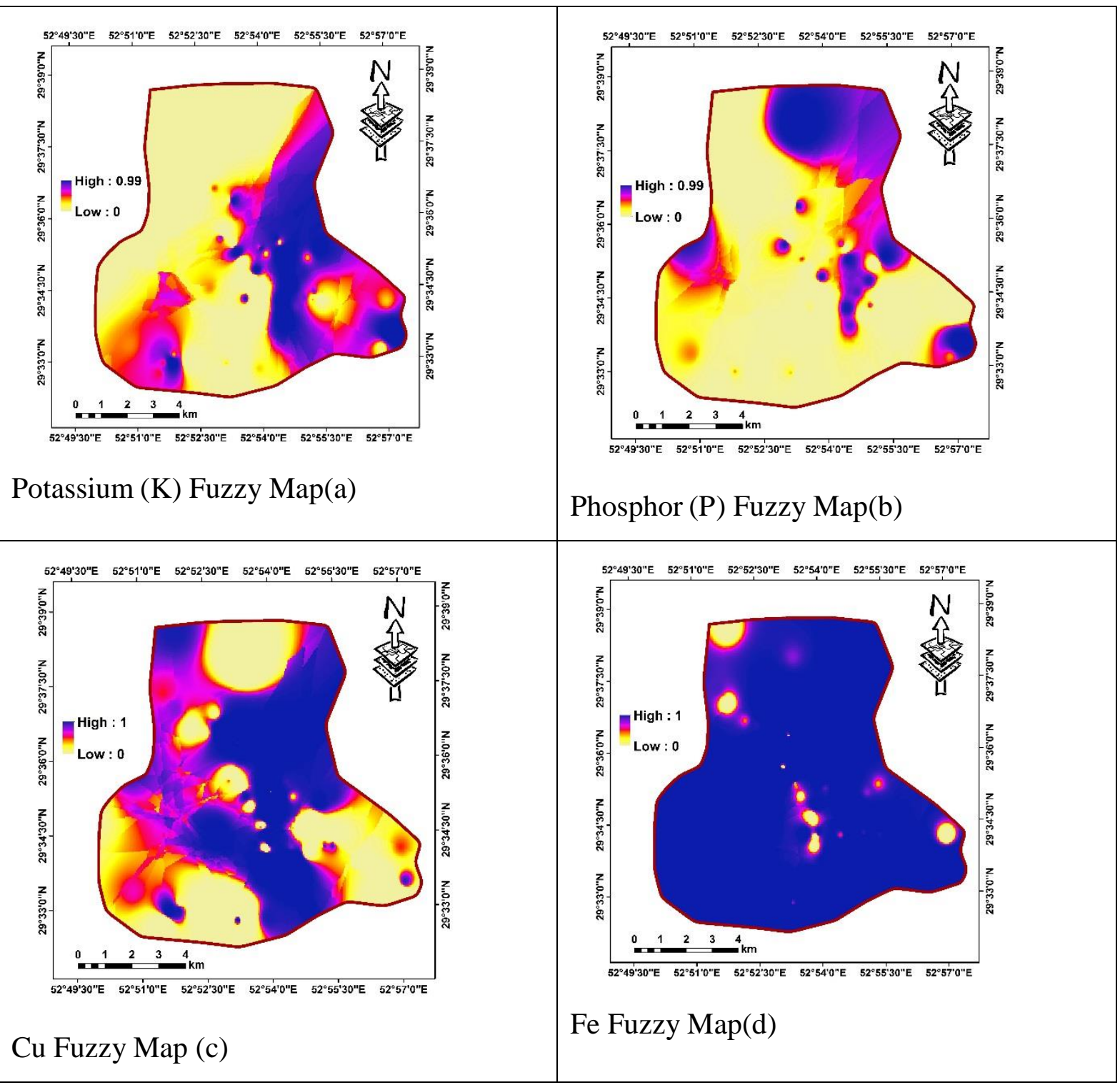




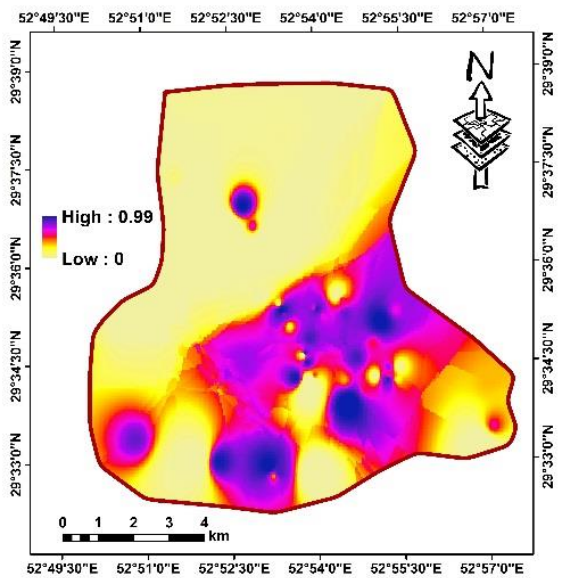

OC Fuzzy MAP (f)

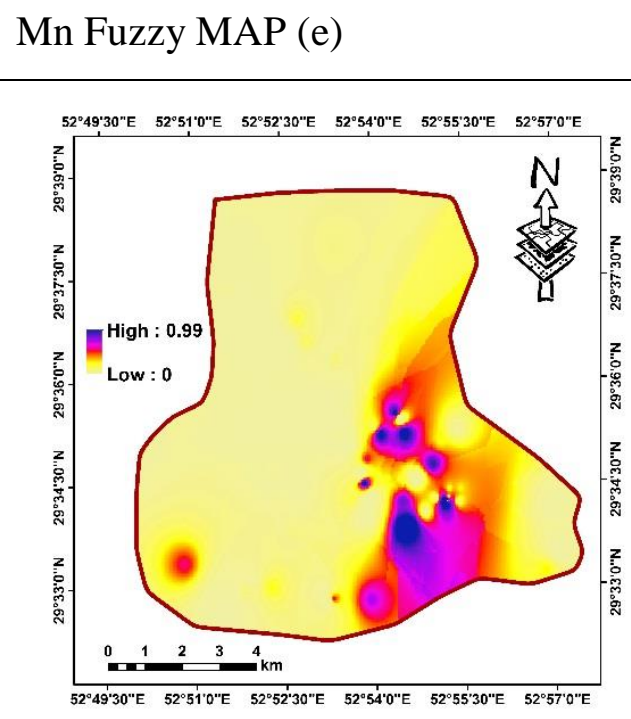

\section{Zn Fuzzy MAP (g)}

Figure 4. Fuzzy map of studied area for each soil fertility parameter. (a):K; (b):P (c):CU, (d):Fe; (e):Mn; (f):OC; (g): Zn.

According to Figure 4 most of the study area did not have a suitable value for Mn parameter that in the fuzzy map had the value close to zero (critical limit $=10(\mathrm{mg} / \mathrm{kg})$ ). While the results of fuzzy method showed that most of the study area (the parts of east, southeast and the small parts of south west of the study area) had suitable values for $\mathrm{P}$ and $\mathrm{Zn}$ parameters that had the value close to 1 in fuzzy map 165 (critical limit= and for $\mathrm{P}$ and $\mathrm{Zn}$ respectively). Parts of north, south west and south of the study area 
Solid Earth Discuss., doi:10.5194/se-2016-17, 2016

Manuscript under review for journal Solid Earth

Published: 2 March 2016

(c) Author(s) 2016. CC-BY 3.0 License.

(c) (1)

were not suitable for fertility (critical limit=). According to the fuzzy map of K parts of north, southeast and west were not suitable (critical limit=). Also parts of north, northwest and south of the study area were not suitable for $\mathrm{Cu}$. Finally it was determined that only parts of northeast, southeast and the small parts of west and east were suitable for soil fertility.

Finally to overt each parameter and to prepare the soil fertility OWA method was used. OWA offers a wealth of possible solutions for our residential developmental problems. In our application, seven order weights were applied corresponding to the seven factors that were rank-ordered for each parameter after the modified factor weights were applied. Table 3, gives six typical sets of order weights for the seven 175 factors: (1) average level of risk and full trade-off, (2) low level of risk and no trade-off, (3) high level of risk and no trade- off, (4) low level of risk and average trade-off, (5) high level of risk and average trade-off, (6) average level of risk and no trade-off. Figure 5 shows the locations of typical sets of order weights in the decision-support space (Figure 5).

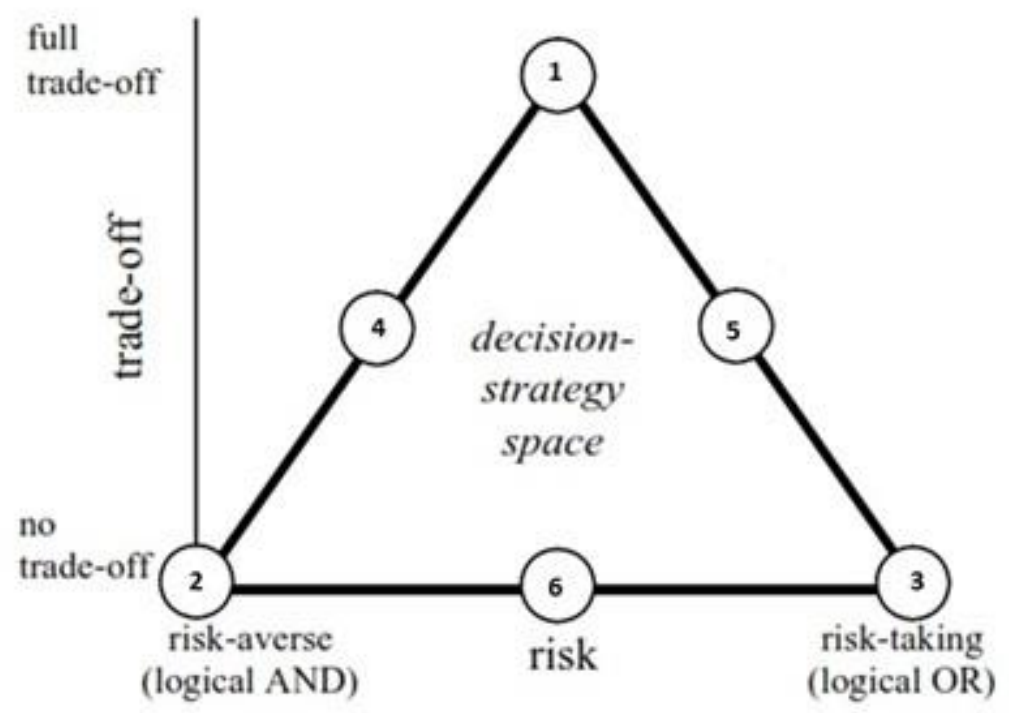

180 Figure 5. Decision-strategy space and typical sets of order weights (see Table 3) 
Table 3: Typical sets of order weights for seven factors.

\begin{tabular}{|c|c|c|c|c|c|c|c|}
\hline & \multicolumn{7}{|c|}{ (1) Average level of risk and full trade-off } \\
\hline order weight & 0.1428 & 0.1428 & 0.1428 & 0.1428 & 0.1428 & 0.1428 & 0.1428 \\
\hline rank & $1^{\text {st }}$ & $2^{\text {nd }}$ & $3^{\text {rd }}$ & $4^{\text {th }}$ & $5^{\text {th }}$ & $6^{\text {th }}$ & $7^{\text {th }}$ \\
\hline & \multicolumn{7}{|c|}{ (2) Low level of risk and no trade-off } \\
\hline order weight & 1 & 0 & 0 & 0 & 0 & 0 & 0 \\
\hline \multirow[t]{2}{*}{ rank } & $1^{\text {st }}$ & $2^{\text {nd }}$ & $3^{\text {rd }}$ & $4^{\text {th }}$ & $5^{\text {th }}$ & $6^{\text {th }}$ & $7^{\text {th }}$ \\
\hline & \multicolumn{7}{|c|}{ (3) High level of risk and no trade-off } \\
\hline order weight & 0 & 0 & 0 & 0 & 0 & 0 & 1 \\
\hline \multirow[t]{2}{*}{ rank } & $1^{\text {st }}$ & $2^{\text {nd }}$ & $3^{\text {rd }}$ & $4^{\text {th }}$ & $5^{\text {th }}$ & $6^{\text {th }}$ & $7^{\text {th }}$ \\
\hline & \multicolumn{7}{|c|}{ (4) Low level of risk and average trade-off } \\
\hline order weight & 0.4455 & 0.2772 & 0.1579 & 0.0789 & 0.0320 & 0.0085 & 0 \\
\hline \multirow[t]{2}{*}{ rank } & $1^{\text {st }}$ & $2^{\text {nd }}$ & $3^{\text {rd }}$ & $4^{\text {th }}$ & $5^{\text {th }}$ & $6^{\text {th }}$ & $7^{\text {th }}$ \\
\hline & \multicolumn{7}{|c|}{ (5) High level of risk and average trade-off } \\
\hline order weight & 0 & 0.0085 & 0.032 & 0.0789 & 0.1579 & 0.2772 & 0.4455 \\
\hline \multirow[t]{2}{*}{ rank } & $1^{\text {st }}$ & $2^{\text {nd }}$ & $3^{\text {rd }}$ & $4^{\text {th }}$ & $5^{\text {th }}$ & $6^{\text {th }}$ & $7^{\text {th }}$ \\
\hline & \multicolumn{7}{|c|}{ (6) Average level of risk and no trade-off } \\
\hline order weight & 0 & 0 & 0 & 1 & 0 & 0 & 0 \\
\hline rank & $1^{\text {st }}$ & $2^{\text {nd }}$ & $3^{\text {rd }}$ & $4^{\text {th }}$ & $5^{\text {th }}$ & $6^{\text {th }}$ & $7^{\text {th }}$ \\
\hline
\end{tabular}

185 Given the standardized criterion maps and corresponding criterion weights, we apply the OWA operator using Eq. (2) for selected values of fuzzy quantifiers: at least one, at least a few, a few, identity, most, almost all, and all are used. Each quantifier is associated with a set of order weights that are calculated according to Eq. (2). Figure 6 shows the six alternative soil fertility patterns. 
Solid Earth Discuss., doi:10.5194/se-2016-17, 2016

Manuscript under review for journal Solid Earth

Published: 2 March 2016

(c) Author(s) 2016. CC-BY 3.0 License.

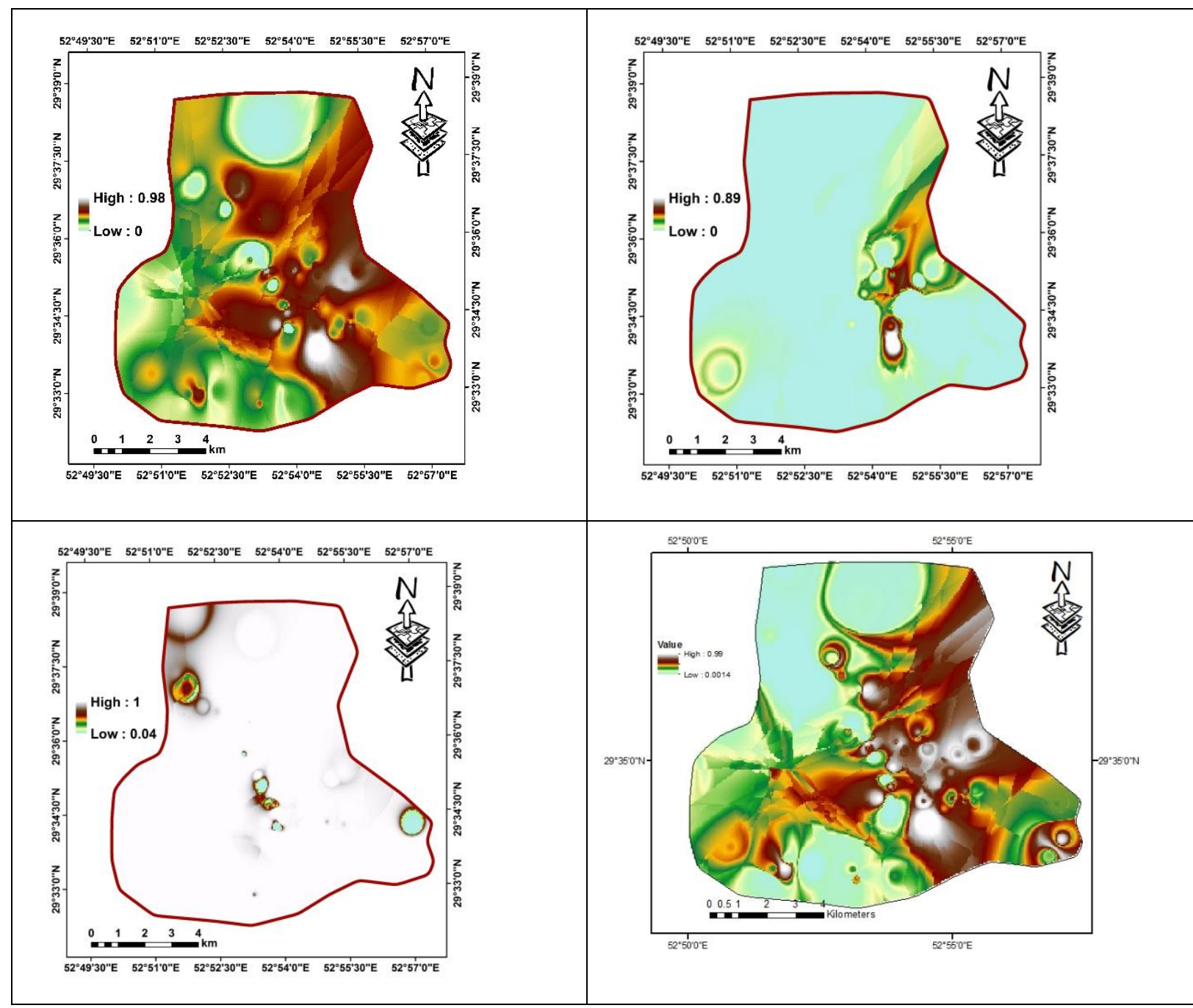




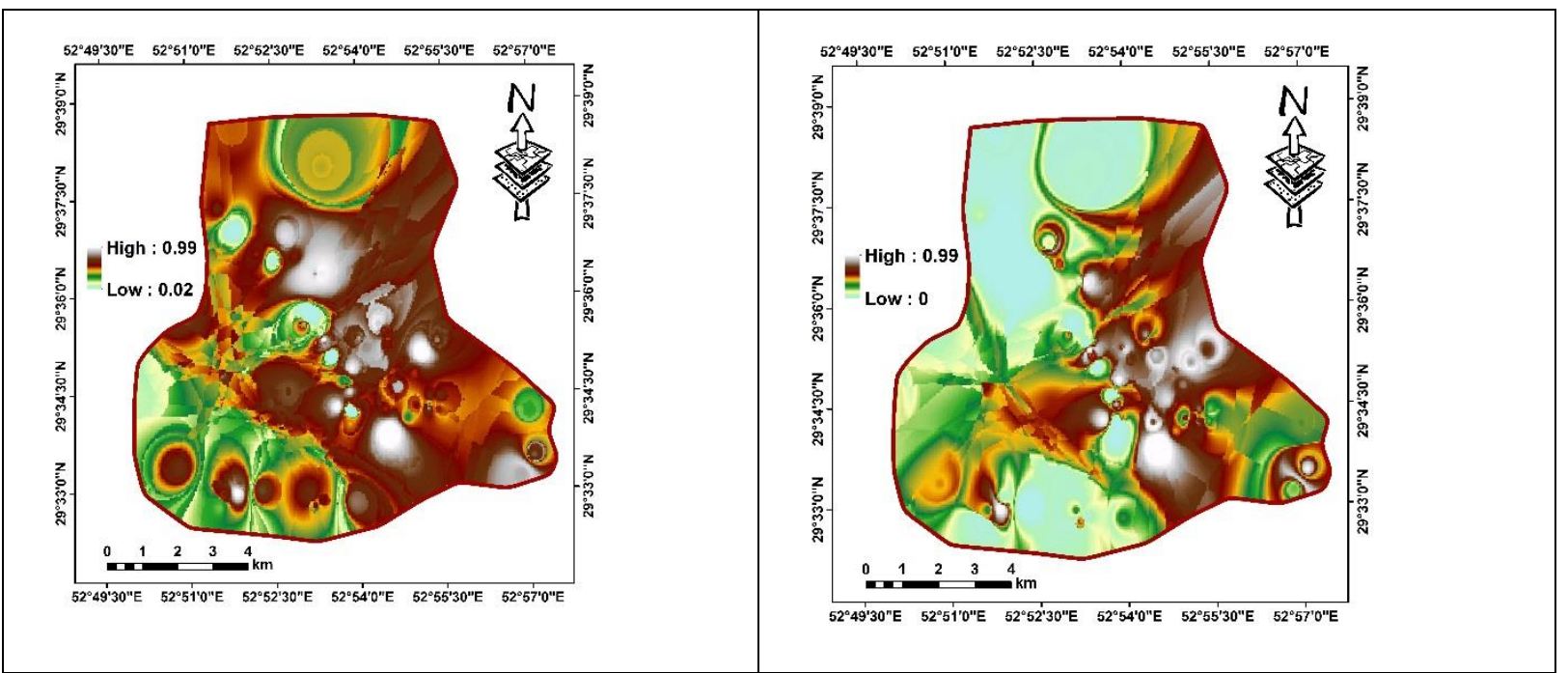

Figure 6. Soil fertility maps of OWA results for selected fuzzy linguistic quantifiers

According to Figure 6 (1) the parts of the study area had high value for soil fertility (high risk level for farmers with good financial conditions). According to Figure 6 (2), with decreasing risk (no trade-off), the area with high soil fertility was determined. So, only the parts of west and southwest of the study area were suitable for soil fertility. While almost all of the parts were not suitable for soil fertility. According to Figure 6 (3) almost all of the study area had low soil fertility. The Figure 6 (4) showed 195 low risk with average trade-off that in comparison of Figure 6 (2) had more risk. The Figure 6 (5) showed high risk with average trade-off that in comparison of Figure 6 (3) had lower risk for the determination of soil fertility. Figure 6 (6) showed average risk with no trade-off that in comparison of Figure 6 (3) had more risk. Based on Table 4, the OWA map was classified in four classes that is shown in Figure 7 and Figure 8. 
Solid Earth Discuss., doi:10.5194/se-2016-17, 2016

Manuscript under review for journal Solid Earth

Published: 2 March 2016

(c) Author(s) 2016. CC-BY 3.0 License.

\section{(c) (1)}

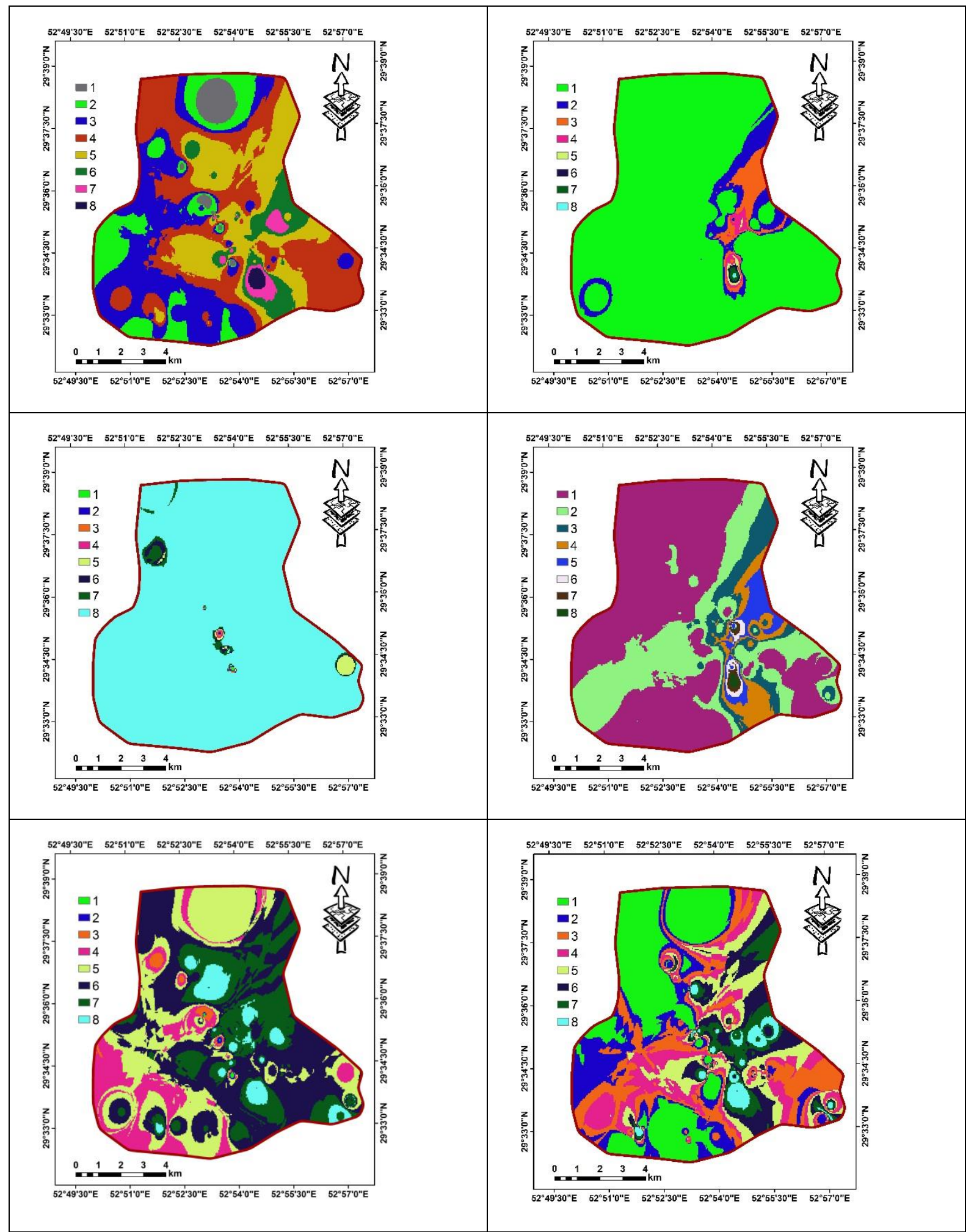


Solid Earth Discuss., doi:10.5194/se-2016-17, 2016

Manuscript under review for journal Solid Earth

Published: 2 March 2016

(C) Author(s) 2016. CC-BY 3.0 License.

(c) (i)

200 Fig 7. OWA map were classified in eight classes

Table 4. Description of each classes for soil fertility

\begin{tabular}{|l|l|l|}
\hline & Range & Description \\
\hline 1 & $0-0.125$ & \multirow{2}{*}{ Very low } \\
\cline { 1 - 2 } 2 & $0.125-0.25$ & \\
\hline 3 & $0.25-0.375$ & Low \\
\cline { 1 - 2 } 4 & $0.375-0.5$ & \multirow{2}{*}{ Medium } \\
\cline { 1 - 2 } 5 & $0.5-0.625$ & \\
\hline 6 & $0.625-0.75$ & \multirow{2}{*}{ Very high } \\
\cline { 1 - 2 } 7 & $0.75-0.875$ & \\
\hline 8 & $0.875-1$ & \multicolumn{1}{|l}{} \\
\cline { 1 - 2 }
\end{tabular}


Solid Earth Discuss., doi:10.5194/se-2016-17, 2016

Manuscript under review for journal Solid Earth

Published: 2 March 2016

(c) Author(s) 2016. CC-BY 3.0 License.

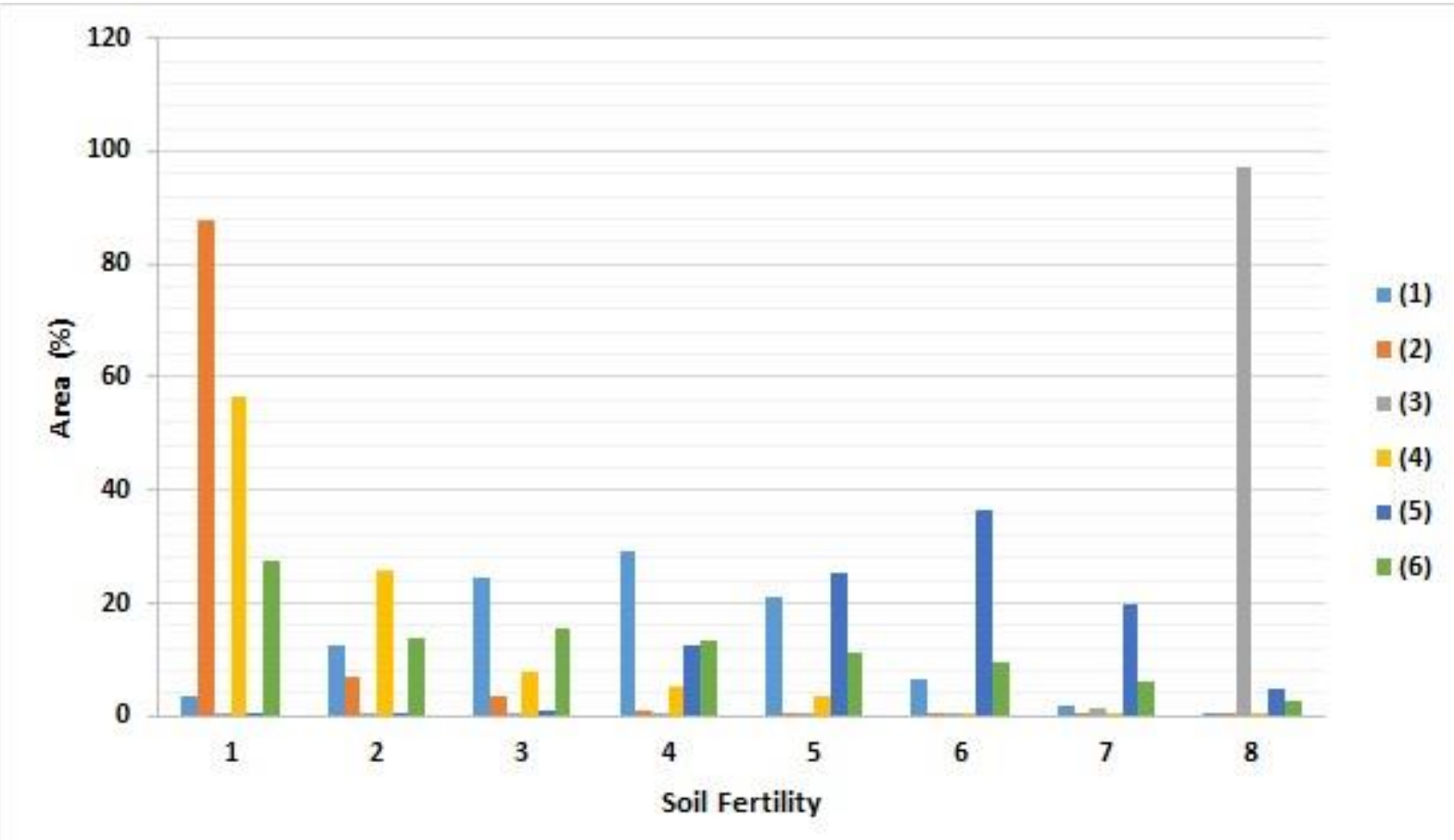

Figure 8. Area of each classes using OWA method.

Based on Table 4, the OWA map was classified in eight classes that is shown in Figure 7 and Table 5. The results in the study are similar to another research by Mokarram and Aminzadeh (2010), in that they used seven order weights for land suitability. The newest research for different agricultural issues such as soil fertility is by Khaki et al. (2015), Bijanzadeh and Mokarram (2013) and Mokarram 210 Marzieh, Bardideh Mehdi (2012) in order to determine soil fertility used fuzzy algorithm. In this research only medium risk (AHP) was used and the researchers did not check different risk levels. In the total, it is stated that using OWA method with difference risk levels can create several maps that can help a user (for example farmer) to make different decisions, according to different financial situations and different risk levels. For example with low risk, the farmer can select an area that has more soil 215 fertility to yield maximum produce. So OWA can be applied for fields of natural science to make accurate decisions. 
Table 5. Area $\left(\mathrm{km}^{2}\right)$ of each classes using OWA method for soil fertility.

\begin{tabular}{crrrrrr}
\hline class & \multicolumn{1}{c}{$(1)$} & \multicolumn{1}{c}{$(2)$} & $(3)$ & \multicolumn{1}{c}{$(4)$} & \multicolumn{1}{c}{$(5)$} & $(6)$ \\
\hline 1 & 3.39 & 87.98 & 0.03 & 56.48 & 0.05 & 27.70 \\
2 & 12.68 & 6.97 & 0.04 & 25.82 & 0.10 & 13.89 \\
3 & 24.45 & 3.62 & 0.04 & 7.82 & 0.84 & 15.69 \\
4 & 29.23 & 0.87 & 0.06 & 5.09 & 12.55 & 13.20 \\
5 & 21.26 & 0.25 & 0.69 & 3.41 & 25.17 & 11.20 \\
6 & 6.60 & 0.16 & 0.59 & 0.73 & 36.69 & 9.38 \\
7 & 1.83 & 0.15 & 1.34 & 0.44 & 19.76 & 6.25 \\
8 & 0.59 & 0.03 & 97.23 & 0.24 & 4.86 & 2.70 \\
\hline
\end{tabular}

\section{Conclusions}

It has been tried to show the benefits of the fuzzy approach to GIS-based multicriteria analysis. This is especially true in situations involving a large number of criterion maps. The OWA approach provides a mechanism for guiding the decision maker/analyst through the multicriteria combination procedures.

225 OWA method is an important tool in the management sciences and operational researches. Types of decision rules with definitions in OWA method lead to solve semi-structured decision problems. Drobne and Lisec (2009) for the determination of six designs with different risk level used OWA for seven factors for soil fertility analysis. In fact using OWA can produce an almost infinite range of possibilities for different designs. Mokarram and Aminzadeh (2010) used the seven order weights for 230 soil fertility. In fact using OWA method can produce a variety of decisions based on risk level. So OWA method provides possibility of cultivation for farmers with weak financial (low risk) and good financial (high risk). We suggest the use of OWA method for the agriculture science and other natural sciences. 


\section{References}

1. Ashrafi, Kh., Shafiepour, M. Ghasemi, L. and B. NajarAraabi. 2012. Prediction of Climate Change Induced Temperature Rise in Regional Scale Using Neural Network, International Journal of Environmental Research 6 (3), 677-688.

2. Asproth, V., Holm berg, S. C. a nd A. Håka nsson. 1999. D e c is ion sup port for s p at ial planning and management of human settlements', in Lasker, G.E. (Ed.): Advances in Support Systems Research, Vol. 5, International Institute for Advanced Studies in Systems Research and Cybernetics, Windsor, Ontario, Canada, pp.30-39.

3. Basso, B., De Simone, L.,Cammarano, D., Martin, E.C., Margiotta, S., Grace, P.R.,Yeh, M.L. and T.Y. Chou. 2012. E valu ating Responses to Land Degradation Mitigation Measures in Southern Italy, International Journal of Environmental Research 6 (2), 367-380.

4. Beedasy, J., and D. Whyatt. 1999. Diverting the tourists: aspatial decisionsupport system for tourism planning on a developing island. Journal of Apply Earth Observ. Geoinformation. 3/4, 163-174.

5. Belkhiri, L., Boudoukha, A., an d L. Mouni. 2011. A multivariate Statistical Analysis of Groundwater Chemistry Data, International Journal of Environmental Research 5 (2), 537 544.

6. Burrough, P.A., and R.A. McDonnell. 1998. Principles of geographical information systems. Spatial Information System and Geostatistics. Oxford University Press, New York.

7. Eastman, J. R. 1997. IDRISI for Windows, Version 2.0: Tutorial Exercises, Graduate School of Geography, Clark University, Worcester.

8. Feng, X.Y., and Luo, G.P., Li, C.F., Dai, L. and L. Lu. 2012.Dynamics of Ecosystem Service Value Caused by Land use Changes in ManasRiver of Xinjiang, China, International Journal of Environmental Research 6 (2), 499-508.

9. Fumagalli, N. and A. Toccolini. 2012. Relationship Between Greenways and Ecological Network: A Case Study in Italy, International Journal of Environmental Research 6 (4), 903 916. 
Solid Earth Discuss., doi:10.5194/se-2016-17, 2016

Manuscript under review for journal Solid Earth

Published: 2 March 2016

(c) Author(s) 2016. CC-BY 3.0 License.

10. Organization of Agriculture Jahad Fars province (http://www.fajo.ir).

11. Jiang, H., and J.R. Eastman. 2000. Application of fuzzy measures in multi-criteria evaluation in GIS. International Journal of Geography Information System 14, 173-184.

12. Kanokporn, K. and V. Iamaram. 2011. Ecological Impact Assessment; Conceptual Approach for Better Outcomes, Int. J. Environ. Res., 5 (2), 435-446.

13. Kim, D.K., Jeong, K.S., McKay, R.I.B., Chon, T. S. and G. J. Joo. 2012 . M a chine Learning for Predict iv e Management: Short and L on g term Prediction of Phytoplankton Biom ass u sing Genetic Algorithm Based Recurrent Neural Networks, International Journal of Environmental Research 6 (1), 95-108.

14. Liu, X., J. Malczewski. 2013. GIS-Based Local Ordered Weighted Averaging: A Case Study in London, Ontario. Electronic Thesis and Dissertation Repository. Paper 1227.

15. Makropoulos, C., Butler, D., and C. Maksimovic. 2003. A fuzzy logic spatial decision support system for urban water management. J. Water Resour. Plann. Manage. 129 (1),69-77.

16. Malczewski, J. 2006. Ordered weighted averaging with fuzzy quantifiers: GIS-based multicriteria evaluation for land-use suitability analysis. International Journal of Applied Earth Observation and Geoinformation. 8: 270-277.

17. Malczewski, J. 1996. A GIS-based approach to multiplecriteria group decision making. International Journal of Geographical Information Systems 10(8), 955-971.

18. Malczewski, J. 1999. GIS and Multicriteria Decision Analysis. John Wiley \& Sons Inc., New York.

19. Malczewski, J. 2004. GIS-based land-use suitability analysis: a critical overview. Progr. Plann. $62(1), 3-65$.

20. Malczewski, J., Chapman, T., Flegel, C., Walters, D., Shrubsole, D., and M.A. Healy. 2003. GIS-multicriteria evaluation with ordered weighted averaging (OWA): case study of developing watershed management strategies. Environ. Plann. A 35 (10), 1769-1784.

21. Malczewski, J., and C. Rinner. 2005. Exploring multicriteria decision strategies in GIS with linguistic quantifiers: a case study of residential quality evaluation. Journal of Geography System 7 (2), 249-268. 
Solid Earth Discuss., doi:10.5194/se-2016-17, 2016

Manuscript under review for journal Solid Earth

Published: 2 March 2016

(c) Author(s) 2016. CC-BY 3.0 License.

22. Mendes, J.F.G. and W.S. Motizuki. 2001.Urban quality of life evaluation scenarios: the case of sãocarlos in Brazil. CTBUH Review, 1 (2), 1-10.

23. Mokarram M., and F. Aminzadeh. 2010. GIS-based multicriteria land suitability evaluation using ordered weight averaging with fuzzy quantifier: a case study in Shavur plain, Iran. The International Archives of the Photogrammetry, Remote Sensing and Spatial Information Sciences, Vol. 38, Part II.

24. Nejadi, A., Jafari, H.R., Makhdoum, M. F. and M. Mahmoudi. 2012.Modeling Plausible Impacts of land use change on $\mathrm{w}$ ildlife $\mathrm{h}$ abitats, Application an $\mathrm{d}$ validation : Lisar protected area, Iran, International Journal of Environmental Research 6 (4), 883-892.

25. Rasouli, S., MakhdoumFarkhondeh, M., Jafari, H .R., Suffling,R., Kiabi, B. and A. R. Yavari. 2012. Assessment of Ecological integrity in a landscape con text using the Miankalepeninsula of Northern Iran, Int. J. Environ. Res., 6 (2), 443-450.

26. Salehi, E., Zebardast, L. and A. R. Yavri. 2012. Detecting Forest Fragmentation with Morphological Image Processing in Golestan National Park in northeast of Iran, International Journal of Environmental Research 6 (2), 531-536.

27. Sanaee., M. FallahShamsi, S. R. and H. FerdowsiAsemanjerdi. 2010. Multi-criteria land evaluation, using WLC and OWA strategies to select suitable site of forage plantation (Case study; Zakherd, Fars). Rangeland, 4 (2), 216-227.

28. Shumilov, O.I., Kasatkina, E.A., Mielikainen, K., Timonen, M. and A.G. Kanatjev. 2011. Palaeovolcanos, Solar activity and pine tree-rings from the Kola Peninsula (northwestern Russia) over the last 560 years, International Journal of Environmental Research 5 (4),855864.

29. Soufi M. 2004. Morpho-climatic classification of gullies in fars province, southwest of i.r. iran . International Soil Conservation Organisation Conference - Brisbane.

30. Yager, R.R. 1988. On ordered weighted averaging aggregation operators in multi-criteria 315 decision making. IEEE Trans. Syst. Man Cybernet. 18 (1), 183-190.

31. Yager, R.R. 1996. Quantifier guided aggregation using OWA operators. Int. J. Intell. Syst. 11, 49-73. 
Solid Earth Discuss., doi:10.5194/se-2016-17, 2016

Manuscript under review for journal Solid Earth

Published: 2 March 2016

(c) Author(s) 2016. CC-BY 3.0 License.

32. Drobne, S., Lisec A. 2009. Multi-attribute Decision Analysis in GIS: Weighted Linear Combination and Ordered Weighted Averaging. Informatica 33 (2009) 459-474.

33. B. Delsouz Khaki, N. Honarjoo, N. Davatgar, A.Jalalian, H. Torab. 2015. Soil Fertility Evaluation Using Fuzzy Membership Function (Case Study: Southern Half of Foumanat Plain in North of Iran). Allgemeine forst undjagdzeitung. 53-64P.

34. Mokarram M, Bardideh M. 2012. Soil fertility evaluation for wheat cultivation by fuzzy theory approache and compared with boolean method and soil test method in gis area. Agronomy journal (pajouhesh \& sazandegi). Volume 25 , number 3 (96); page(s) $111-123$.

35. Bijanzadeh E, Mokarram, M. 2013. The use of fuzzy- AHP methods to assess fertility classes for wheat and its relationship with soil salinity: east of Shiraz, Iran : A case study. AUSTORALIUN journal of crop science. 7(11):1699-1706 
Solid Earth Discuss., doi:10.5194/se-2016-17, 2016

Manuscript under review for journal Solid Earth

Published: 2 March 2016

(c) Author(s) 2016. CC-BY 3.0 License.

\section{Figure captions}

Figure 1. Location of the study area (digital elevation model (DEM) with spatial resolution of $30 \mathrm{~m}$ ) 335 (Source: http://earthexplorer.usgs.gov).

Figure 2. Position of sample points for the study area.

Figure 3. Interpolation map using IDW method. (a):Cu; (b):Fe; (c):K; (d):Mn; (e):OC; (f):P; (g): Zn.

Figure 4. Fuzzy map of studied area for each soil fertility parameter. (a):Cu; (b):Fe; (c):K; (d):Mn; (e):OC; (f):P; (g): Zn.

340 Figure 5. Decision-strategy space and typical sets of order weights (see Table 3)

Figure 6. Soil fertility maps of OWA results for selected fuzzy linguistic quantifiers

Figure 7. Classification of OWA map for soil fertility.

Figure 8. Area of each classes using OWA method. 